\title{
Morphological study of the lingual papillae in the barking deer, Muntiacus muntjak.
}

\begin{abstract}
The morphology of the tongue of the adult barking deer, Muntiacus muntjak, was examined by light and scanning electron microscopy. The result showed that the tongue of the barking deer was elongated with a rounded apex. Four types of lingual papillae were observed: filiform, fungiform, vallate and large conical papillae. The filiform papillae represented the most numerous types of lingual papillae. The fungiform papillae were distributed among the filiform papillae on the rostral and the body portions of the tongue. Ten to thirteen vallate papillae were distributed on both sides of the lingual prominence among the large conical papillae. Histologically, both the fungiform and vallate papillae contain taste buds in the epithelial layer. The distribution and types of lingual papillae found in the barking deer are similar to those in the other species that belong to the family Cervidae.
\end{abstract}

Keyword: Morphology; Lingual papillae; Barking deer. 